\title{
Eriocaulaceae da região serrana do estado do Rio de Janeiro, Brasil
}

\author{
Eriocaulaceae from the serrana region of Rio de Janeiro state, Brazil
}

\author{
Hudson de Medeiros Villela Freitas ${ }^{1} \&$ Marcelo Trovó $^{1}$
}

\begin{abstract}
Resumo
Eriocaulaceae compreende 10 gêneros e cerca de 1200 espécies distribuídas nos trópicos. A maioria destas espécies são ervas em roseta que portam inflorescência do tipo capítulo. Embora muitos estudos taxonômicos em Eriocaulaceae já tenham sido realizados na Cadeia do Espinhaço, principal centro de diversidade da família, pouco se conhece da diversidade fora dela. No estado do Rio de Janeiro, ainda são escassos os dados sobre riqueza, abundância e distribuição geográfica das espécies de Eriocaulaceae. O presente trabalho apresenta o tratamento florístico das Eriocaulaceae ocorrentes na região serrana, que representa a porção norte da Serra do Mar no estado do Rio de Janeiro. Foi registrada a ocorrência de oito espécies distribuídas em quatro gêneros: uma de Syngonanthus, uma de Leiothrix, uma de Tonina e cinco de Paepalanthus. São apresentadas ilustrações, descrições, chave de identificação, além de comentários sobre distribuição geográfica e variação morfológica das espécies.
\end{abstract}

Palavras-chave: flora, florística, Paepalanthus, Serra dos Órgãos, taxonomia.

\begin{abstract}
Eriocaulaceae comprises 10 genera and circa of 1200 species distributed in the tropics. Most of these species are rosulate herbs bearing a capitulum. Although many taxonomic treatments of Eriocaulaceae from the Espinhaço Range, the family main diversity center, are already published, the information about the species outside of this area is still lacking. In the state of Rio de Janeiro, the data on species richness, abundance, and geographical distribution of the Eriocaulaceae species are unavailable. This manuscript is the floristic treatment of the Eriocaulaceae from the serrana region of Rio de Janeiro state. A total of eight species was recorded, those distributed in four genera: one of Syngonanthus, one of Leiothrix, one of Tonina, and five of Paepalanthus. Species illustrations, descriptions, and an identification key, as well as comments on geographical distribution and morphological variation are provided.
\end{abstract}

Key words: flora, floristics, Paepalanthus, Serra dos Órgãos, taxonomy.

\section{Introdução}

Eriocaulaceae é uma família de monocotiledôneas que abrange cerca de 1200 espécies distribuídas em 10 gêneros. Possui distribuição pantropical, ocorrendo geralmente em formações campestres e áreas alagadas (Giulietti \& Hensold 1990; Stützel 1998; Sano 2004). As espécies que compõem a família são, em geral, ervas de pequeno porte, anuais ou perenes, aquáticas ou terrestres e apresentam diminutas flores diclinas, ou mais raramente monoclinas (Watanabe et al. 2015), dispostas em inflorescências capituliformes (Koernicke 1863; Ruhland 1903; Giulietti \& Hensold 1990; Stützel 1998). Tais inflorescências são sustentadas por escapos que, muitas vezes, são utilizadas em ornamentações e comercializadas com o nome de "sempre vivas". Especialmente espécies de Syngonanthus Ruhland e Comanthera L.B.Sm. são exportadas anualmente para os Estados Unidos e Europa. (Giulietti \& Hensold 1990; Stützel 1998; Schmidt et al. 2007).

\footnotetext{
${ }^{1}$ Universidade Federal do Rio de Janeiro, Lab. Integrado de Sistemática Vegetal, Depto. Botânica, Inst. Biologia, Av. Carlos Chagas Filho 373, $21941-590$, Rio de Janeiro, Brasil.hudbio@gmail.com,martrovo@gmail.com

${ }^{2}$ Autor para correspondência: martrovo@gmail.com
} 
Ruhland (1903) dividiu Eriocaulaceae em duas subfamílias: Eriocauloideae e Paepalanthoideae. Tal divisão tomou como base o trabalho de Koernicke (1863) e utilizou-se somente de caracteres florais. Enquanto Eriocauloideae reúne espécies com flores diplostêmones com glândulas nas pétalas, Paepalanthoideae apresenta espécies com flores isostêmones sem glândulas nas pétalas (Koernicke 1863; Ruhland 1903) O centro de diversidade da família, em especial de Paepalanthoideae, é a Cadeia do Espinhaço em Minas Gerais e na Bahia (Giulietti \& Hensold 1990). No Brasil, são encontradas aproximadamente 625 espécies distribuídas em oito gêneros, sendo que 558 são endêmicas do país (BFG 2015).

Os estudos florísticos e taxonômicos em Eriocaulaceae estão concentrados na Cadeia do Espinhaço em Minas Gerais e na Bahia (Giulietti \& Parra 1995; Hensold 1998; Parra 1998; Sano 1998; Miranda \& Giulietti 2001; Sano et al. 2010; Andrino \& Costa 2013; Andrino et al. 2015) No entanto, a diversidade em outras áreas é significativa (BFG 2015). No Rio de Janeiro, estima-se que ocorram cerca de 35 espécies distribuídas nos mais variados ambientes (Oliveira 2014). Os dois únicos tratamentos florísticos neste estado estão relacionados a áreas de restinga, onde ocorrem 12 espécies (Contaifer et al. 2013; Silva \& Trovó 2014). Este trabalho tem como objetivo principal contribuir com o levantamento da diversidade e conservação das espécies de Eriocaulaceae no Rio de Janeiro, sanando a falta de informações sobre as espécies que ocorrem na região serrana do estado.

\section{Material e Métodos}

O presente trabalho tem como base a análise de espécimes de Eriocaulaceae depositados nos herbários CESJ, HB, GUA, R, RB, RFA, SP e SPF. Foram realizadas quatro expedições de coleta em diferentes pontos da região serrana do estado do Rio de Janeiro em unidades de conservação. entre março de 2012 e março de 2015. Neste trabalho, consideramos como região serrana do estado do Rio de Janeiro toda a extensão da cadeia montanhosa que se estende entre os municípios de Petrópolis ao sul e Santa Maria Madalena ao norte (CIDE 1998), representando a porção norte da Serra do Mar no estado do Rio de Janeiro. A região apresenta clima do tipo $\mathrm{CW}$ de Köpen temperado, com altitude aproximada de 350 a 2300 metros e solos predominantemente graníticos (Cardozo et al. 2008).
Para as descrições das estruturas vegetativas e florais utilizamos a terminologia proposta por Radford (1974) e por Weberling (1989), respectivamente. Apresentamos uma chave de identificação para todas as espécies, além de descrições, comentários e ilustrações.

\section{Resultados e Discussão}

Neste trabalho, registramos oito espécies distribuídas em quatro gêneros. Paepalanthus Mart. é o gênero que apresenta maior riqueza, contando com 5 espécies. Leiothrix Ruhland, Syngonanthus e Tonina Aubl. são representados por uma espécie. Todas as espécies foram encontradas em ao menos uma Unidade de Conservação. Cinco espécies foram encontradas em áreas abertas e secas, enquanto Paepalanthus macaheensis Körn foi coletada em sub-bosque de matas nebulares e Syngonanthus caulescens (Poir.) Ruhland e Tonina fluviatilis Aubl. foram coletadas em áreas úmidas. Destacamos o registro de $T$. fluviatilis, uma vez que a espécie é em geral referida para regiões litorâneas.

A maioria das espécies que ocorrem na região serrana do Rio de Janeiro são espécies de ampla distribuição, tais como Leiothrix flavescens (Bong.) Ruhland, Paepalanthus tortilis (Bong.) Koern., Syngonanthus caulescens e Tonina fluviatilis. Algumas espécies são compartilhadas com regiões montanhosas adjacentes, tais como Paepalanthus dupatya Mart. ex Körn., Paepalanthus macaheensis e Paepalanthus caparoensis Ruhland. Apenas Paepalanthus ovatus Körn. é de ocorrência exclusiva da região serrana do Rio de Janeiro, sendo a única espécie endêmica do estado (BFG 2015).

Em relação ao total de espécies ocorrentes no estado do Rio de Janeiro, a região serrana contribui com aproximadamente vinte e cinco por cento das espécies atualmente aceitas (Oliveira 2014; BFG 2015). A região possui uma riqueza um pouco menor que a encontrada nas restingas deste mesmo estado, onde ocorrem 12 espécies (Silva \& Trovó 2014) e uma riqueza semelhante à encontrada no Parque Nacional do Itatiaia, onde ocorrem nove espécies (Freitas 2015). A composição predominantemente granítica dos solos de toda a região serrana é um provável fator limitante da riqueza de espécies na área. A serra do Caparaó, que está geograficamente próxima, conta com apenas 4 espécies de Eriocaulaceae (Trovó et al. 2007). Já o Parque Estadual do Ibitipoca, que possui encraves quartizíticos em sua composição do solo, apresenta uma riqueza significativamente maior, abrigando 22 espécies de Eriocaulaceae (Ferreira et al. 2011). 


\section{Chave de identificação para as espécies de Eriocaulaceae da região serrana do Rio de Janeiro}

1. Flores pistiladas com pétalas unidas na região mediana................................ Syngonanthus caulescens

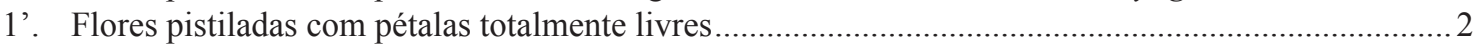

2. Espatas abertas; pétalas das flores pistiladas reduzidas a lobos.......................... Tonina fluviatilis

2'. Espatas fechadas; pétalas das flores pistiladas desenvolvidas

3. Capítulos amarelados a dourados; anteras basifixas; ramos estigmáticos e nectaríferos inseridos em diferentes alturas no estilete Leiothrix flavescens

3'. Capítulos nunca amarelados a dourados; anteras dorsifixas; ramos estigmáticos e nectaríferos inseridos na mesma altura no estilete.

4. Escapos coalescidos; inflorescência formada por diversos capítulos

4'. Escapos livres; inflorescência formada por um único capítulo..................................... 5

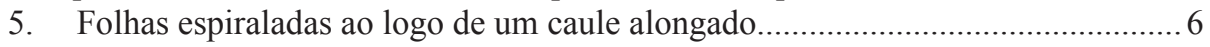

5'. Folhas dispostas em roseta de caule curto.......................................................... 7

6. Capítulos enegrecidos; brácteas florais negras............. Paepalanthus tortilis

6'. Capítulos brancos a ocre; brácteas florais castanha

Paepalanthus macaheensis

7. Folhas membranáceas; brácteas involucrais negras; flores estaminadas com ca. $4 \mathrm{~mm}$

.Paepalanthus ovatus

7'. Folhas cartáceas; brácteas involucrais castanho-escuras; flores estaminadas com ca. $2 \mathrm{~mm}$ Paepalanthus caparoensis

1. Leiothrix flavescens (Bong.) Ruhland, Pflanzenr. IV (Heft 13): 231. $1903 . \quad$ Fig. 1a Plantas 10-47 cm compr. Folhas em roseta, $9,2-4,3 \times 0,6-0,7 \mathrm{~cm}$, cartáceas, lanceoladas, com tricomas em ambas as faces, margem ciliada, ápice arredondado a agudo. Espatas fechadas, 7,6-9,3 cm compr., ápice agudo, com tricomas. Escapos livres, 7,5-41,3 cm compr., com tricomas. Capítulos amarelados a dourados; brácteas involucrais douradas a castanhas, ca. $3 \mathrm{~mm}$ compr., lanceoladas, ápice agudo, ciliadas, pilosas; brácteas florais hialinas a douradas no ápice, ca. $4 \mathrm{~mm}$ compr., obovadas, ápice obtuso, ciliadas, glabras. Flores estaminadas ca. $3 \mathrm{~mm}$ compr.; pedicelo ca. $1 \mathrm{~mm}$ compr., com longos tricomas; sépalas hialinas, obovadas, ciliadas, glabras, ápice obtuso; tubo da corola hialino; anteras basifixas; pistilódios 3, papilosos. Flores pistiladas ca. $3 \mathrm{~mm}$ compr.; pedicelo ca. $1 \mathrm{~mm}$ compr., com longos tricomas; sépalas livres, obovadas, hialinas com apice dourado e obtuso, ciliadas, glabras; pétalas livres, hialinas, obovadas, ápice agudo, ciliadas, glabras; ramos estigmáticos simples, inseridos no estilete em diferentes alturas dos ramos nectaríferos.

Leiothrix flavescens pode ser distinguida das demais espécies ocorrentes na região serrana do Rio de Janeiro por possuir folhas de ápice geralmente arredondado, capítulos amarelados a dourados, anteras basifixas e ramos estigmáticos e nectaríferos se inserindo em pontos distintos do estilete. A espécie apresenta ampla distribuição geográfica na América do Sul, compreendendo uma grande variação em caracteres vegetativos e reprodutivos (BFG 2015; Giulietti \& Hensold 1991). No Rio de Janeiro, ocorre disjuntamente em populações esparsas em campos de altitude da região serrana e nas restingas do Estado (Silva \& Trovó 2014). Foi encontrada com flores e frutos nos meses de setembro e novembro.

Material examinado: Petrópolis, 18.XI.2009, R. Borges et al. 1015 (RB); Teresópolis, 27.IX.2007, G. Heiden 910 (RB).

2. Paepalanthus caparoensis Ruhland, Pflanzenr. IV (Heft 13): 145. 1903.

Fig. $1 \mathrm{~b}$

Plantas 9-27 cm compr.. Folhas cartáceas, em roseta, 2,5-3,2 × 0,2-0,3 cm, lanceoladas, com tricomas geralemente longos em ambas as faces, margem ciliada, ápice agudo. Espatas fechadas, 1,5-5 cm compr., ápice agudo, com tricomas. Escapos livres, 3,1-23,5 cm compr., com tricomas. Capítulos brancos; brácteas involucrais castanhoescuras, ca. $2 \mathrm{~mm}$ compr., ovais, ápice agudo, ciliadas, pilosas; brácteas florais castanho-escuras, ca. $2 \mathrm{~mm}$ compr., ovais, ápice agudo, ciliadas, glabras. Flores estaminadas ca. $2 \mathrm{~mm}$ compr.; pedicelo ca. $1 \mathrm{~mm}$ compr., com longos tricomas; sépalas castanho escuras, obovadas, ciliadas, 

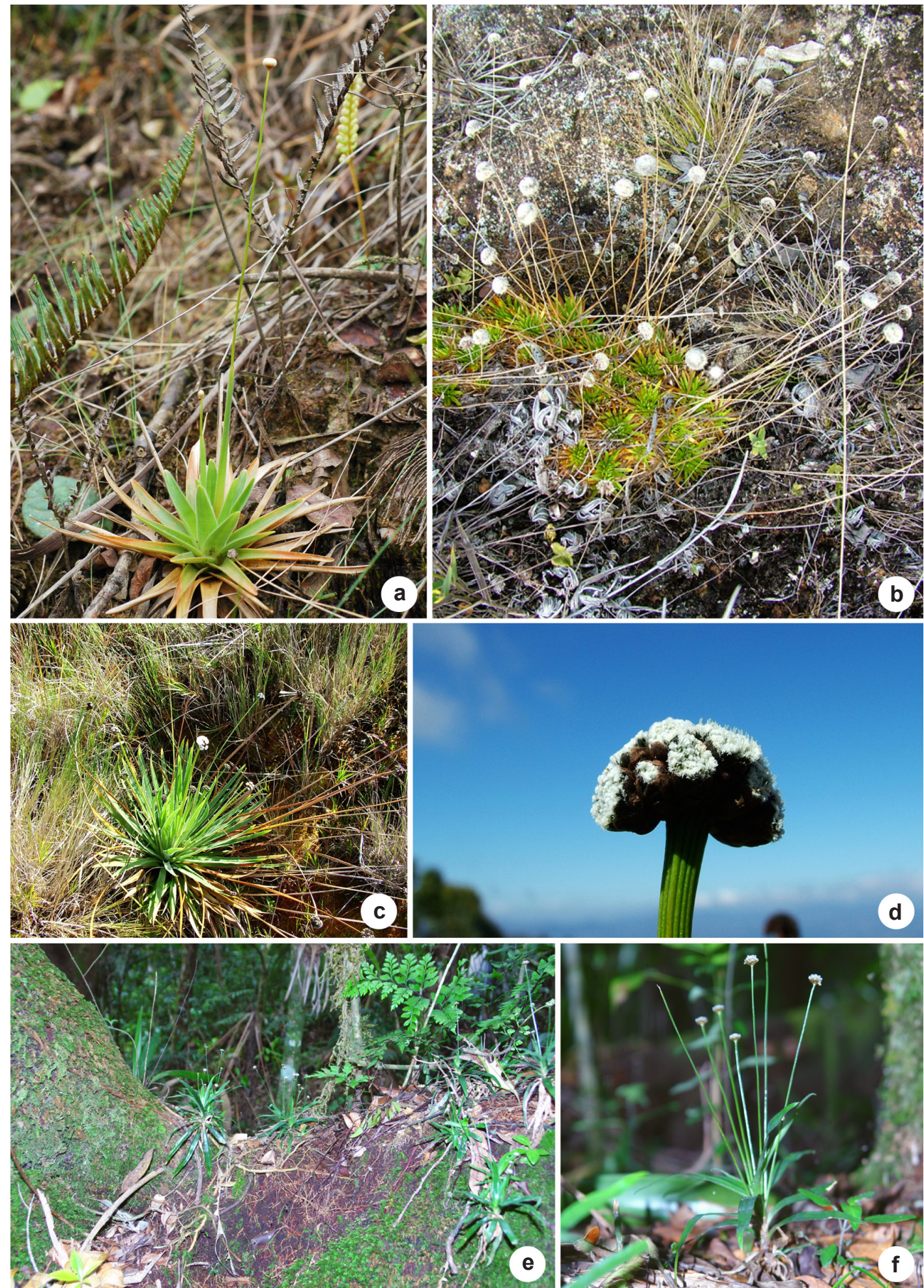

Figura 1 - Hábito e detalhes das espécies de Eriocaulaceae ocorrentes na região serrana do estado do Rio de Janeiro - a. Leiothrix flavescens; b. Paepalanthus caparoensis; c,d. Paepalanthus dupatya; e,f. Paepalanthus macaheensis (Fotos: a. J.G. Rohwer; b-d. M. Trovó; e,f. C.N. Fraga).

Figure 1 - Habit and details of the Eriocaulaceae species from the região serrana of the Rio de Janeiro State - a. Leiothrix flavescens; $\mathrm{b}$. Paepalanthus caparoensis; c,d. Paepalanthus dupatya; e,f. Paepalanthus macaheensis (Photos: a. J.G. Rohwer; b-d. M. Trovó; e,f. C.N. Fraga). 
glabras, ápice obtuso; tubo da corola hialino; anteras dorsifixas; pistilódios 3, papilosos. Flores pistiladas ca. $2 \mathrm{~mm}$ compr.; séssil; sépalas castanho escuras, obovadas, ápice obtuso, ciliadas, glabras; pétalas livres, hialinas, obovadas, ápice obtuso, ciliadas, glabras; ramos estigmáticos bífidos, inseridos no estilete na mesma altura que os ramos nectaríferos.

Paepalanthus caparoensis pode ser distinguido das demais espécies ocorrentes na região serrana do Rio de Janeiro por possuir folhas cartáceas restritas à roseta com tricomas geralmente longos. É muito semelhante à $P$. ovatus, espécie que possui folhas membranáceas com tricomas mais curtos. Sendo as duas espécies simpátricas, é possível que formem híbridos naturais. Paepalanthus uleanus Ruhland está sendo sinonimizada nesta espécie (Sano et al. in preparation) A espécie é bastante frequente no Parque Nacional do Caparaó (Trovó et al. 2007). Na região serrana do Rio de Janeiro, ocorre com baixa frequência em diversas áreas de campos de altitude (BFG 2015). Foi encontrada com flores e frutos principalmente entre os meses de setembro e março. Material examinado: Macaé, 16.IX.1982, G. Martinelli \& C. Farney 8700 (RB); Nova Friburgo, 2.VI.1987, L.C. Giordano \& D.P. Costa 296 (RB); 30.III.1989, L.S. Sylvestre et al. 202 (RB); 8.VIII.1989, A. Amorim et al. 155 (RB); Petrópolis, 27.I.1983, G. Martinelli \& E. Simonis 8996 (RB); 25.VII.1983, G. Martinelli et al. 9337 (RB); 31.III.1986, Porembski et al. 2841 (RB); 13.III.2006, G. Martinelli et al.16063 (RB).

\section{Paepalanthus dupatya Mart. ex Körn., in Fl.} bras. (Martius) 3(1): 410. $1863 . \quad$ Fig. 1c,d Plantas 35-60 cm compr. Folhas cartáceas, em roseta, 11-23,2 × 0,4-1,3 cm, linear-lanceoladas, com tricomas em ambas as faces, margem ciliada, ápice agudo. Espatas fechadas, 9-13 cm compr., ápice agudo, com tricomas. Escapos coalescidos, 13-48 cm compr., com tricomas. Capítulos brancos; brácteas involucrais castanho, ca. 3 mm compr., ovais, ápice acuminado-mucronado, ciliadas, pilosas; brácteas florais castanho, ca. 3 mm compr., oblongas, ápice agudo-acuminado, ciliadas, glabras. Flores estaminadas ca. $3 \mathrm{~mm}$ compr.; pedicelo ca. $1 \mathrm{~mm}$ compr., com longos tricomas; sépalas castanho, obovais, ciliadas, glabras, ápice obtuso; tubo da corola hialino; anteras dorsifixas; pistilódios 3, papilosos. Flores pistiladas ca. $3 \mathrm{~mm}$ compr.; pedicelo ca. $1 \mathrm{~mm}$ compr.; sépalas castanho, obovais, ápice agudo, ciliadas, glabras; pétalas livres, hialinas, obovais, ápice agudo, ciliadas, glabras; ramos estigmáticos bífidos, inseridos no estilete na mesma altura que os ramos nectaríferos.
Paepalanthus dupatya pertence a Paepalanthus subg. Platycaulon Koern. e pode ser facilmente distinguido das demais espécies ocorrentes na região serrana do Rio de Janeiro por possuir escapos coalescidos formando inflorescências compostas por mais de um capítulo. A espécie apresenta distribuição geográfica restrita à Serra do Mar em São Paulo, região serrana do Rio de Janeiro e algumas serras de Minas Gerais (BFG 2015). No Rio de Janeiro, é conhecida por apenas uma coleta recente nos campos de altitude no município de Nova Friburgo. Foi encontrada com flores e frutos no meses de abril.

Material examinado: Nova Friburgo, 20.IV.2014, C.B. Gomes et al. 68 (RB).

4. Paepalanthus macaheensis Körn., Vidensk. Meddel. Naturhist. Foren. Kjøbenhavn 20-22: 311. 1871.

Fig. 1e,f

Plantas 12-20 cm compr.. Folhas cartáceas, ao longo de um caule alongado, 5-14 × 0,2-0,5 $\mathrm{cm}$, lanceoladas, com tricomas em ambas as faces, margem glabrescente, ápice agudo. Espatas fechadas, 2-4 cm compr., ápice agudo, com tricomas. Escapos livres, 9-16,5 cm compr., com tricomas. Capítulos alvos a ocre; brácteas involucrais castanho escuras, ca. $2 \mathrm{~mm}$ compr., ovais, ápice agudo, ciliadas, glabras; brácteas florais castanho, ca. $2 \mathrm{~mm}$ compr., obovadas, ápice arredondado, ciliadas, glabras. Flores estaminadas ca. $2 \mathrm{~mm}$ compr.; pedicelo ca. $1 \mathrm{~mm}$ compr., com longos tricomas; sépalas castanho escuras, obovadas, ciliadas, glabras, ápice arredondado; tubo da corola hialino a castanho; anteras dorsifixas; pistilódios 3, papilosos. Flores pistiladas ca. $3 \mathrm{~mm}$ compr.; séssil a curtamente pedicelada; sépalas castanho, oblongas a navicular, ápice agudo, ciliadas em direção ao ápice, pilosas na parte superior da face abaxial; pétalas livres, hialinas, oblongas, ápice agudo, ciliadas em direção ao ápice, pilosas na porção superior da face abaxial; ramos estigmáticos bífidos, inseridos no estilete na mesma altura que os ramos nectaríferos.

Paepalanthus macaheensis pode ser facilmente distinguido das demais espécies ocorrentes na região serrana do Rio de Janeiro por possuir caule alongado e escapos alvos a ocre. A espécie é a única que ocorre em sub-bosque de matas nebulares, característica única em Eriocaulaceae (Trovó \& Sano 2015). Ocorre nos estados do Espírito Santo, Minas Gerais e Rio de Janeiro (BFG 2015). No Rio de Janeiro, é conhecida por poucas coletas em sub-bosques da 
região serrana do estado. Foi encontrada com flores e frutos entre os meses de dezembro e fevereiro.

Material examinado: Nova Friburgo, II.1900, G. Ule (R). Santa Maria Madalena, 17.XII.1986, G. Martinelli et al. 12007 (RB); Serra dos Órgãos, 16.I.1883, Saldanha 6718 (R); 1887, J.T. Moura (R).

\section{Paepalanthus ovatus Körn., in Fl. Bras.} (Martius) 3(1): 367. 1863.

Fig. 2a

Plantas 3-23 cm compr.. Folhas membranáceas, em roseta, $0,5-6 \times 0,1-0,3 \mathrm{~cm}$, lanceoladas, com tricomas em ambas as faces, margem ciliada, ápice agudo. Espatas fechadas, 1,5-4,5 cm compr., ápice agudo, com tricomas. Escapos livres, 3-20 cm compr., com tricomas. Capítulos alvos; brácteas involucrais negras, ca. $3 \mathrm{~mm}$ compr., ovais, ápice agudo, ciliadas, pilosas; brácteas florais castanho com ápices negros, ca. $4 \mathrm{~mm}$ compr., obovadas, ápice agudo, ciliadas, glabras. Flores estaminadas ca. $4 \mathrm{~mm}$ compr.; pedicelo ca. $1 \mathrm{~mm}$ compr., com longos tricomas; sépalas castanho com ápices negros, obovadas, ciliadas, glabras, ápice obtuso; tubo da corola hialino; anteras dorsifixas; pistilódios 3, papilosos. Flores pistiladas ca. $2 \mathrm{~mm}$; séssil; sépalas hialinas, obovadas, ápice obtuso, ciliadas, glabras; pétalas livres, hialinas, obovadas, ápice obtuso, ciliadas, glabras; ramos estigmáticos bífidos, inseridos no estilete no mesmo ponto que os ramos nectaríferos.

Paepalanthus ovatus é a espécie mais frequente na região serrana do Rio de Janeiro e pode ser distinguida das demais espécies por possuir folhas membranáceas dispostas em rosetas com curtos tricomas. Sua grande semelhança com $P$. caparoensis foi discutida acima, sendo P. ovatus uma espécie muito mais frequente nos campos de altitude. É a única espécie endêmica do estado do Rio de Janeiro, ocorrendo por toda extensão da região serrana (BFG 2015). Foi encontrada com flores e frutos praticamente o ano todo, em especial de outubro a março.

Material examinado: Macaé, 16.IV.1985, G. Martinelli et al. 10703 (RB); Nova Friburgo, 20.VI.1987, L.C. Giordano 301 (RB); 26.IX.2009, C.N. Fraga \& M.M. Saavedra 2559 (RB); Petrópolis, 15.V.1986, G. Martinelli et al. 11580 (RB); 18.IX.2009, R. Borges et al. 992 (RB); 12.II.2011, R. Borges et al. 1174 (RB); Teresópolis, 8.IX.1929, A.C. Brade 9938 (R); I.1952, J. Vidal II-200 (R); I.1952, J. Vidal II-266 (R); II.1952, J. Vidal II-329 (R); II.1952, J. Vidal II-677 (R); XII.1952, J. Vidal II-5690 (R); XII.1952, J. Vidal II-5697 (R); XII.1952, J. Vidal II-5774 (R); II.1953, J. Vidal II-6439 (R); II.1953, J. Vidal II-6440 (R); II.1953, J. Vidal II-6458 (R); II.1953, J. Vidal II-6459 (R); II.1953,
J. Vidal II-6468 (R); V.1953, J. Vidal II-6698 (R); 21.VII.1970, J. Barria 115 (R); 27.IX.2007, G. Heiden $910 a$ (RB); 12.IV.2011, J.A. Lombardi et al. 8195 (RB); Sem Localidade, 20.III.1932, A.C. Brade 11485 (R); 12.I.1960, E. Santos 97 (R).

6. Paepalanthus tortilis (Bong.) Körn., in Fl. Bras. (Martius) 3(1): 354. 1863.

Fig. $2 b$

Plantas $12-17 \mathrm{~cm}$ compr.. Folhas membranáceas, ao longo de um caule alongado, $1,2-2 \times 0,1-0,2 \mathrm{~cm}$, lanceoladas, com tricomas em ambas as faces, margem glabra, ápice agudo. Espatas fechadas, 1-2,5 cm compr., ápice agudo, com tricomas. Escapos livres, 9-16 cm compr., pilosos. Capítulos enegrecidos; brácteas involucrais negras, ca. 2 mm compr., ovais, ápice agudo, não ciliadas, glabras; brácteas florais castanho escuras, ca. $1 \mathrm{~mm}$ compr., obovadas, ápice agudo, com tricomas. Flores estaminadas ca. $2 \mathrm{~mm}$ compr.; pedicelo $1 \mathrm{~mm}$ compr., glabro; sépalas negras, obovadas, ciliadas, pilosas, ápice obtuso; tubo da corola hialino; anteras dorsifixas; pistilódios 3, papilosos. Flores pistiladas ca. $1 \mathrm{~mm}$ compr.; pedicelo ca. 0,5 $\mathrm{mm}$ compr., glabro; sépalas castanho com margens enegrecidas, obovadas, ápice obtuso, ciliadas, glabras; pétalas livres, hialinas, obovadas, ápice obtuso, ciliadas, com tricomas; ramos estigmáticos bífidos, inseridos no estilete no mesmo ponto que os ramos nectaríferos.

Paepalanthus tortilis pode ser facilmente distinguida das demais espécies ocorrentes na região serrana do Rio de Janeiro por possuir um caule alongado, do qual, no ápice, partem escapos que portam capítulos enegrecidos. A espécie apresenta distribuição geográfica bastante ampla na América do Sul, sendo uma das espécies de Eriocaulaceae mais amplamente distribuídas (BFG 2015). Tal distribuição é provavelmente reflexo de sua estratégia de dispersão pelo vento, que parece ser bastante eficiente (Trovó \& Stützel 2011). No Rio de Janeiro, ocorre disjuntamente nas restingas (Silva \& Trovó 2014) e nos campos de altitude da região serrana. Foi encontrada com flores e frutos no mês de julho.

Material examinado: Nova Friburgo, 15.VII.1975, $P$. Ochioni 7621 (RFA).

7. Syngonanthus caulescens (Poir.) Ruhland, Pflanzenr. IV (Heft 13): 267. $1903 . \quad$ Fig. 2c

Plantas 11-30 cm compr. Folhas membranáceas, ao longo de um caule alongado, $1-4,5 \times 0,1-0,4 \mathrm{~cm}$, lanceolada, com tricomas em ambas as faces, margem com tricomas, ápice agudo. 


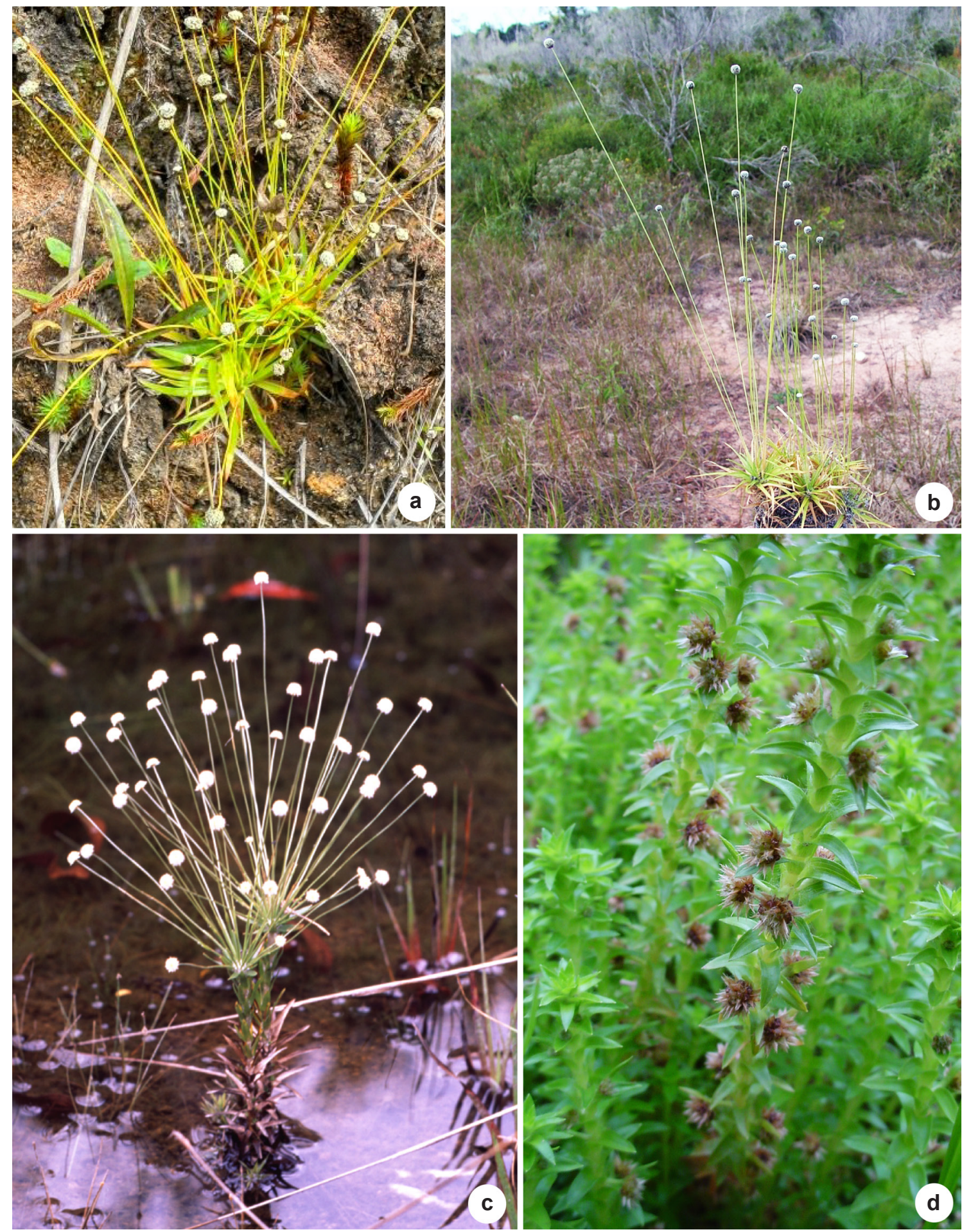

Figura 2 - Hábito e detalhes das espécies de Eriocaulaceae ocorrentes na região serrana do estado do Rio de Janeiro a. Paepalanthus ovatus; b. Paepalanthus tortilis; c. Syngonanthus caulescens; d. Tonina fluviatilis (Fotos: a. H.M.V. Freitas; b. M. Trovó; c. T. Stützel; d. S.E. Martins).

Figure 2 - Habit and details of the Eriocaulaceae species from the região serrana of the Rio de Janeiro state - a. Paepalanthus ovatus; b. Paepalanthus tortilis; c. Syngonanthus caulescens; d. Tonina fluviatilis (Photos: a. H.M.V. Freitas; b. M. Trovó; c. T. Stützel; d. S.E. Martins). 
Espatas fechadas, 1-4,5 cm compr., ápice agudo, com tricomas. Escapos livres, 3-21 cm compr., com tricomas. Capítulos cremes a alvos; brácteas involucrais creme, ca. $2 \mathrm{~mm}$ compr., ovais, ápice agudo, glabra; brácteas florais hialinas, ca. $2 \mathrm{~mm}$ compr., obovadas, ápice agudo, glabras. Flores estaminadas ca. 2,5 mm compr.; pedicelo ca. 1 $\mathrm{mm}$ compr., com longos tricomas; sépalas creme, ovais, glabras, ápice agudo; tubo da corola hialino; anteras dorsifixas; pistilódios 3, papilosos; flores pistiladas ca. 2,5 mm compr.; pedicelo ca. 0,5 $\mathrm{mm}$ compr., glabro; sépalas hialinas, ovais, ápice agudo, glabras; pétalas unidas na região distal, hialinas, obovadas, ápice acuminado, glabras; ramos estigmáticos simples, inseridos no estilete na mesma altura que os ramos nectaríferos.

Syngonanthus caulescens pode ser facilmente distinguida das demais espécies ocorrentes na região serrana do Rio de Janeiro por possuir um caule alongado, do qual partem escapos portando inflorescências cremes a alvos. As flores pistiladas desta espécie possuem as pétalas fusionadas na porção central, característica não compartilhada por nenhuma outra espécie na área deste estudo. A espécie apresenta distribuição geográfica bastante ampla na América do Sul. (BFG 2015). No Rio de Janeiro, é conhecida apenas por coletas em áreas úmidas nos campos de altitude na região serrana do estado. Foi encontrada com flores e frutos entre os meses de janeiro e junho.

Material examinado: Nova Friburgo, 13.IV.1895, E. Ule 4093 (R); 13.V.1944, K. Arens (R); Teresópolis, 8.I.1883, J. Saldanha 6717 (R); I.1888, J.T. Moura (RFA); 25.III.1917, A.J. Sampaio 1949 (R); 27.X.1929, A.C. Brade 9782 (R); VI.1943, Bertha 2004 (R); II.1947, B. Lutz 2228 (R); $A A B 155$ (HB). Sem Localidade, 4.VI.1944, E. Pereira 395 (HB); 1948, L. Rose \& B. Lutz 39 (R).

8. Tonina fluvialitis Aubl., Hist. Pl. Guiane 2: 857. 1775.

Fig. $2 d$

Plantas com aproximadamente $35 \mathrm{~cm}$. Folhas membranáceas, ao longo de um caule alongado, $0,5-1,5 \times 0,1-0,2 \mathrm{~cm}$, lanceoladas, com tricomas em ambas as faces, margem ciliada, ápice agudo. Espatas abertas, 0,5-1 cm compr., ápice agudo, com tricomas. Escapos livres, 0,3-1 cm compr., com tricomas. Capítulos castanhos a alvos; brácteas involucrais castanho-claras, ca. $2 \mathrm{~mm}$ compr., largoelípticas, ápice acuminado, ciliadas, glabrescente; brácteas florais hialinas, ca. $2 \mathrm{~mm}$, lanceoladas, ápice acuminado, ciliadas, face adaxial pilosa e abaxial glabra. Flores estaminadas ca. 2 mm compr.; pedicelo ca. 0,5 mm compr.; sépalas hialinas, obovais, glabras, ápice agudo; tubo da corola hialino; anteras dorsifixas, pistilódios 3, papilosos; flores pistiladas ca. 2,5 mm compr.; subsésseis; sépalas hialinas, a dorsal carenada, as latero-ventrais côncavas, ápice agudo, ciliada, glabrescente; pétalas livres, reduzidas a lobos com longos tricomas, hialinas, ápice agudo, ciliadas, densamente pilosas; ramos estigmáticos bífidos, inseridos no estilete na mesma altura que os ramos nectaríferos.

Tonina fluviatilis é a única espécie do gênero e pode ser facilmente distinguida das demais espécies ocorrentes na região serrana do Rio de Janeiro por possuir um caule alongado reptante que porta espatas abertas, escapos muito curtos e capítulos castanhos a alvos. As flores pistiladas desta espécie apresentam as pétalas reduzidas a lobos com longos tricomas, característica única na família. A espécie apresenta distribuição geográfica bastante ampla, sendo comum em áreas alagadas litorâneas das Américas do Sul e Central (BFG 2015). No Rio de Janeiro é conhecida por espécimes coletados em áreas alagadas de restingas (Silva \& Trovó 2014) e por apenas uma coleta no município de Teresópolis. A ocorrência de T. fluviatilis na região serrana causa um certo estranhamento. É possível que este material seja contenha problemas na etiqueta, embora registros mais interioranos desta espécie tem sido recentemente encontrados no Brasil. Foi encontrada com flores e frutos no mês de maio.

Material examinado: Teresópolis, V.1917, A.J. Sampaio 2633 (R).

\section{Agradecimentos}

Os autores agradecem à FAPERJ, o apoio financeiro dado ao Projeto Inventários da Flora Fluminense, uma abordagem interdisciplinar (E-26/110.031/2011, E-26/111.392/2012, E-26/111010.001.392/2014 - BIOTA); agradecem também a Alexander von Humboldt Foundation, à UFRJ (ALV 2013), ao CNPq (proc. 470349/20131), à FAPERJ (E-26/112.476 - INST), e aos curadores dos herbários visitados.

\section{Referências}

Andrino, C.O. \& Costa, F.N. 2013. Paepalanthus subgen. Xeractis (Eriocaulaceae) na porção central da Cadeia do Espinhaço em Minas Gerais, Brasil. Rodriguésia 64: 75-89.

Andrino, C.O.; Costa, F.N. \& Sano, P.T. 2015. O gênero Paepalanthus Mart. (Eriocaulaceae) no Parque Estadual do Biribiri, Diamantina, Minas Gerais, Brasil. Rodriguésia 66: 393-419. 
BFG. 2015. Growing knowledge: an overview of seed plant diversity in Brazil. Rodriguésia 66: 1085-1113.

Cardozo, S.V.; Pereira, M.G.; Ravelli, A. \& Loss, A. 2008. Caracterização de propriedades edáficas em áreas sob manejo orgânico e natural na região serrana do estado do Rio de Janeiro. Semina, Ciências Agrárias 29: 515-528.

CIDE (Fundação CIDE). 1998. Mapa da Região Serrana do Rio de Janeiro. Disponível em $<$ http://www. zonu.com/brazil_maps/Serrana_Region_Map_Rio_ Janeiro_State_Brazil.htm>. Acesso em $1 \overline{9}$ abril $201 \overline{6}$.

Contaifer, R.B.; Oliveira, A.L.R. \& Bove, C.P. 2013. Flórula do Parque Nacional da Restinga de Jurubatiba, Rio de Janeiro, Brasil: Eriocaulaceae. Arquivos do Museu Nacional 69: 59-66.

Ferreira, C.S.A.M.; Trovó, M. \& Forzza R.C. 2011. A Família Eriocaulaceae no Parque Estadual do Ibitipoca, Minas Gerais, Brasil. Boletim de Botânica da Universidade de São Paulo 29: 19-35.

Freitas, S.N.S. 2015. Diversidade e conservação de Eriocaulaceae na Serra da Mantiqueira, com ênfase no Parque Nacional do Itatiaia. Dissertação de Mestrado, Universidade Federal do Rio de Janeiro, Rio de Janeiro. 52p.

Giulietti, A.M. \& Hensold, N. 1990. Padrões de distribuição geográfica dos gêneros de Eriocaulaceae. Acta Botanica Brasilica 4: 133-159.

Giulietti, A.M. \& Hensold, N. 1991. Nomenclatural changes and range extension in Leiothrix flavescens (Bong.) Ruhland (Eriocaulaceae). Novon 1: 45-49.

Giulietti, A.M. \& Parra, L.R. 1995. Eriocaulaceae. In: Stannard, B.L. Flora of the Pico das Almas, Chapada Diamantina, Bahia, Brasil. The Royal Botanical Gardens, Kew, London. Pp. 684-704.

Hensold, N. 1998. Flora da Serra do Cipó, Minas Gerais: Paepalanthus subg. Xeractis (Eriocaulaceae). Boletim de Botânica da Universidade de São Paulo 17: 207-218.

Koernicke, F. 1863. Eriocaulaceae. In: Martius, C.F.P. \& Eichler, A.W. Flora brasiliensis. Tyopgraphia Regia, München. Vol. 3, pp. 273-307.

Miranda, E.B. \& Giulietti, A.M. 2001. Eriocaulaceae no Morro do Pai Inácio (Palmeiras) e Serra da Chapadinha (Lençóis), Chapada Diamantina, Bahia, Brasil. Sitientibus Série Ciências Biológicas 1: $15-32$.

Oliveira, A.L.R. 2014. Eriocaulaceae. Catálogo das espécies de plantas vasculares e briófitas do estado do Rio de Janeiro. Instituto de Pesquisas Jardim Botânico do Rio de Janeiro, Rio de Janeiro. Disponível em <http://florariojaneiro.jbrj.gov.br>. Acesso em 19 abril 2016.
Parra, L.R. 1998. Flora da Serra do Cipó, Minas Gerais: Syngonanthus Ruhland (Eriocaulaceae). Boletim de Botânica da Universidade de São Paulo 17: 219-254.

Radford, A.E. 1974. Vascular plant systematics. Harper \& Row, New York. 891p.

Ruhland, W. 1903. Eriocaulaceae. In: Engler, A. Das Pflanzenreich. Vol. 4. Wilhelm Engelmann, Leipzig. Pp. 1-294.

Sano, P.T. 1998. Flora da Serra do Cipó, Minas Gerais: Paepalanthus sect. Actinocephalus - Eriocaulaceae. Boletim de Botânica da Universidade de São Paulo 17: 187-205.

Sano, P.T. 2004. Actinocephalus (Körn.) Sano (Paepalanthus sect. Actinocephalus), a new genus of Eriocaulaceae, and other taxonomic and nomenclatural changes involving Paepalanthus Mart. Taxon 53: 99-107.

Sano, P.T.; Giulietti, A.M.; Trovó, M.; Parra, L.R. \& Muller, G. 2010. Flora de Grão-Mogol, Minas Gerais: Eriocaulaceae. Boletim de Botânica da Universidade de São Paulo 28: 125-140.

Silva, L.E.F. \& Trovó, M. 2014. A família Eriocaulaceae nas restingas do Rio de Janeiro, Brasil. Rodriguésia 65: 871-883.

Schmidt, I.B.; Figueiredo, I.B. \& Scariot, A. 2007. Ethnobotany and effects harvesting on the population ecology of Syngonanthus nitens (Bong.) Ruhland (Eriocaulaceae), a NTFP from Japão region, Central Brazil. Economic Botany 61: 73-85.

Stützel, T. 1998. Eriocaulaceae. In: Kubitzki, K. The families and genera of vascular plants IV Flowering Plants: Monocotyledons - Alismatanae and Comelinanae (except Graminae). SpringerVerlag, Berlin. Pp. 197-207.

Trovó, M.; Sano, P.T.; Costa, F.N. \& Giulietti, A.M. 2007. Flora fanerogâmica do Parque Nacional do Caparaó: Eriocaulaceae. Pabstia 17: 2-8.

Trovó, M. \& Sano, P.T. 2015. Shedding light on a species from the shadows: the Paepalanthus macaheensis case (Eriocaulaceae). Phytotaxa 230: 250-258.

Trovó, M. \& Stützel, T. 2011. Diaspores in Eriocaulaceae: morphology, mechanisms, and implications. Feddes Repertorium 122: 456-464.

Watanabe, M.T.C.; Hensold, N. \& Sano, P.T. 2015. Syngonanthus androgynus, a striking new species from South America, its phylogenetic placement and implications for evolution of bisexuality in Eriocaulaceae. Plos One 10: 1-15.

Weberling, F. 1989. Morphology of flowers and inflorescenses. Cambridge University Press, Cambridge. $405 \mathrm{p}$. 